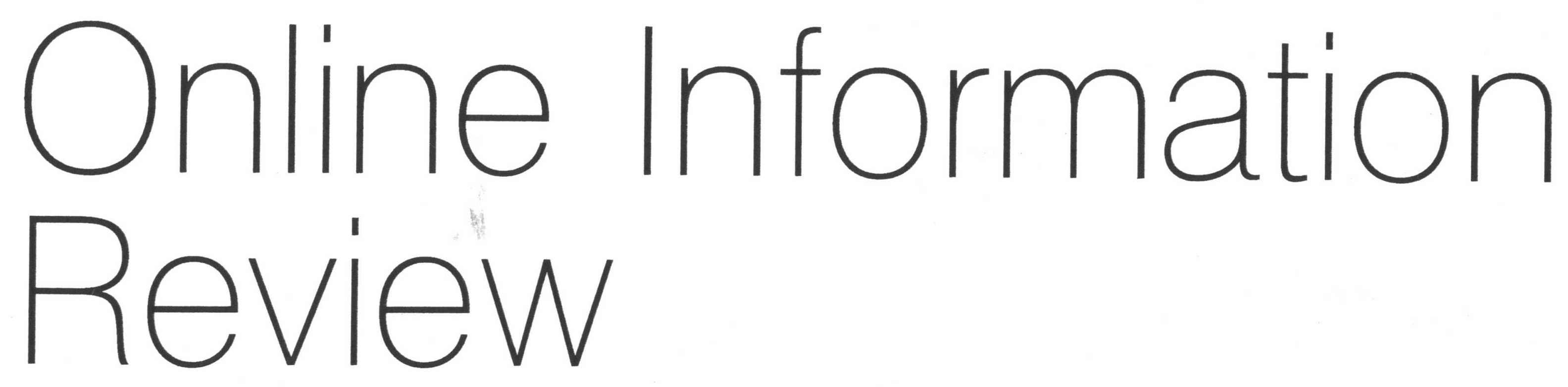

\title{
The impact of electronic resources on humanities graduate student theses
}

\section{Ming-der Wu}

National Taiwan University, Taipei, Taiwan

Shih-chuan Chen

National Taiwan University, Taipei, Taiwan 


\title{
The impact of electronic resources on humanities graduate student theses
}

\author{
Ming-der Wu and Shih-chuan Chen \\ National Taiwan University, Taipei, Taiwan
}

Abstract

Purpose - This study aims to answer the following questions about humanities graduate students: what are the characteristics of the documents cited in their theses? Where and how do they obtain those citations? Do students use and cite electronic resources? Do students favour electronic resources over paper versions?

Design/methodology/approach - The study's participants were 20 humanities graduate students. Following an analysis of the citations in their theses, list-checking and follow-up interviews were conducted.

Findings - The results showed that these humanities graduate students cited considerably more print materials than electronic resources. Most of the documents cited were supplied by the university library. Only a small proportion of the documents were available in electronic format either from the university library or from the internet. The availability ratio of journals was higher than that of books. Students' acceptance of e-journals was higher than that of e-books.

Originality/value - The findings of the study could help researchers and librarians gain a better understanding of how humanities graduate students use electronic resources.

Keywords Graduates, Information research, University libraries

Paper type Research paper

\section{Introduction}

In recent years, university libraries have required considerable financial resources in building electronic collections. Some libraries have cancelled print journal subscriptions and reduced the number of books purchased. Meanwhile e-book databases (which include both current and old monographs) have increased their market share. Google Scholar, which integrates documents from various sources including library holdings, has been a favoured entryway for many people searching for academic information. Convenience and easy access to electronic resources play a key role in changing information-gathering behaviour.

Past studies have shown that people searching for information prefer to use Google rather than to visit the library. To combat growing concern about the demise of the library, university libraries must demonstrate that their investment in electronic collections is worthwhile. George et al. (2006) concluded that even though graduate students heavily use internet resources, the university library remains a key element in their research process. Tenopir's (2003) summary of research studies indicated that electronic library resources were both used and favoured by professors and students alike, and they perceived the electronic format as convenient and time saving.

Compared with undergraduate students, graduate students use more electronic resources. Sutton and Jacoby $(2008$, p. 1) found that graduate students "depend heavily

Impact of ER on student theses 12 August 2009

Approved for publication 24 January 2010

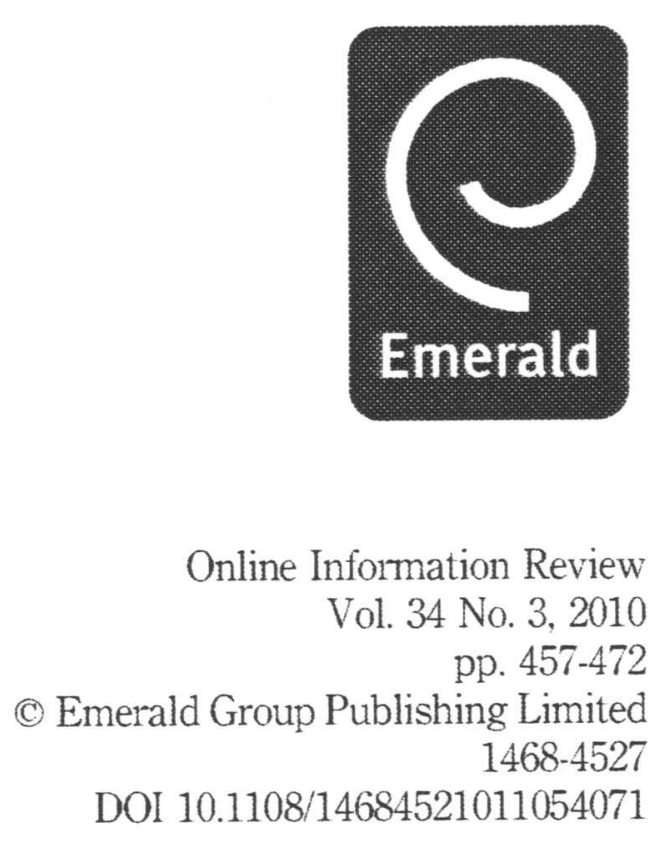


OIR 34,3 on library collections and generally prefer to access materials online". Additionally information behaviour and use patterns may vary among disciplines (Littman and Connaway, 2004; Vakkari and Talja, 2006; Gardiner et al., 2006; Levine-Clark, 2007). Scholars in the humanities were regarded as low-level users of e-journals and databases (Talja and Maula, 2003). However increased availability of electronic resources in the field of humanities may alter this impression. For example Levine-Clark (2007) pointed out that humanities students understood the libraries' e-book services better than students from other disciplines.

Past studies have employed questionnaires and interviews to investigate graduate students' electronic resources usage. The analysis of citations used in graduate theses may reveal the characteristics of resources used, including the electronic format. Specifically this study aims to answer the following questions about humanities graduate students: What are the characteristics of the documents cited in their theses? Where and how do they obtain those citations? Do students use and cite electronic resources? Do students favour electronic resources over paper versions?

\section{Literature review}

American university libraries have reported a growth in expenditure on electronic resources (Case, 2005; Gallagher et al., 2005). It is common for university libraries to gradually cancel print journal subscriptions in order to build larger e-journal collections. Prabha (2007) found that from 2002 to 2006, ARL members' print journal subscriptions decreased 32 per cent while e-journal subscriptions increased 34 per cent. In Taiwan's university libraries, spending on electronic resources increased from 30.01 per cent of a library's budget for materials in 2005 to 35.76 per cent in 2007. Since 2006 the National Science Council has funded a programme of purchasing nationally licensed e-book databases in the humanities and social science fields (Huang, 2008). There has since been a notable increase in the amount of electronic collections in Taiwanese university libraries.

Electronic resources have changed scholars' information behaviour. Liew et al. (2000) indicated that most graduate students preferred to use e-journals over print journals. Students mentioned that e-journals' advantages included hyperlinks to additional sources, search facilities, current documents, around-the-clock availability, and user-friendliness. Siebenberg et al. (2004) indicated that both faculty and students heavily used e-journals; simultaneously however, their use of paper journals also increased. Newby (2005) found that professors and graduate students liked to use e-journals because they were convenient to access. A survey by Hemminger et al. (2007) found that the overwhelming majority (97 per cent) of university science researchers preferred to use electronic databases and journals to search for information. It would be an oversimplification to merely state that the growth of libraries' electronic collections reflects the decline of print materials. Analysing the use studies of e-journals, Rowlands (2007, p. 31) concluded that "print-based and electronic systems are used for different purposes and at different times in the information-seeking cycle". On surveying graduate students' preferences and usage, Liu (2006) concluded that a hybrid information environment was most desired. Electronic and print resources both have advantages and limitations and meet different needs of users.

Theses are the ultimate research outputs of graduate students. Buzzard and New (1983) stated that citation analysis is a valuable approach for evaluating a university 
library's collection support for doctoral research. Cox (2008) indicated that citation analysis provided useful data for making library collection development and management decisions. Walcott (1994) pointed out the significance of investigating the citation behaviour of graduate students, who are the most active users of library collections. When more electronic resources are available, including those on the internet, citation analysis could give researchers and librarians a better understanding of how students use those resources.

Earlier citation studies have shown that electronic resources have little impact on research (Harter, 1998) and represent a low percentage of citations (Zhang, 2001). Analysing the reference lists of articles published in e-journals, Herring (2002, p. 339) found that 16 per cent of citations were electronic resources and stated "online resources are increasingly important to today's scholars and researchers". Furthermore, different methods of analysis may alter the results. Kushkowski (2005) found web citations comprised only 5.4 per cent for e-theses but noted that if print citations with electronic equivalents were also counted, the number would be higher.

Stone (1982) stated that books play a greater role than journals for humanities scholars. According to Reynolds (1995) these scholars use books and older materials and rely heavily on their own personal collections. A citation study by Smith (2003) showed that the monograph is the type of material most cited (71 per cent) by arts and humanities graduate students, while journals were much less cited (19 per cent). Thompson (2002) analysed citations of books on English and American literature and found that books (79.39 per cent) were cited much more than journal articles (12.24 per cent). Analysing the citations of philosophy student theses, Okrent (2001) found that students cited more monographs (56 per cent) and anthologies (18 per cent) than journals (14 per cent). However the availability of full-text electronic files was 11 per cent, 37 per cent, and none respectively.

Although e-books are popular on the internet, and in libraries, they remain unpopular with humanities scholars and students. Wang (2006) stated that humanities scholars did not appreciate e-books and that they preferred to use short articles in e-journals. Levine-Clark (2007) found that only 13 per cent of humanities graduate students frequently used e-books and the remainder used them only once or occasionally. If both print and electronic versions are accessible, only 13.4 per cent of the students would always or usually use e-books. Jamali et al. (2009) explained that high amount of reading required in the humanities renders e-books unsuitable. A study by $\mathrm{Wu}$ and Chen (2007) indicated that all the humanities graduate students used Chinese ancient book databases, but they verified their findings using paper versions. Anderson (2009) stated the quality of original editions as one reason why historians distrust electronic resources. Historians worried about whether an electronic version would be faithful to the original edition and whether annotations or other additions were electronically reliable.

\section{Method}

This study was conducted from January to December 2008. The participants were 20 humanities graduate students who completed their theses and received degrees at the College of Liberal Arts, National Taiwan University (NTU), in the 2007-2008 academic year. They were recruited from the following ten disciplines: Chinese language and literature, foreign languages and literature, Japanese language and literature,
Impact of ER on student theses 
linguistics, history, philosophy, anthropology, art history, musicology, and drama. Invitations were made via e-mail or phone, and two students from each discipline participated. Most (17) were masters' students, and three were doctoral students.

First the citation analysis was conducted. The reference lists from participants' theses were downloaded from the NTU Library's theses and dissertations database. The data collected included the number, type and language of documents cited. The types of books included anthologies. A citation with a URL was noted as a web citation. The years of the oldest, and most current cited documents, were both noted. The lists were then checked against the Library's OPAC to find out whether or not the cited items were held in the Library. It was also noted whether the Library had an electronic version. Internet searches were made to determine whether the item used was available online. Google tools were used, including the Google search engine, Google Scholar, and Google Book Search.

Next the follow-up interviews were conducted to investigate how humanities graduate students gather bibliographic information and documents, use electronic resources, and cite electronic resources as well as to investigate their views on electronic library collections. The critical incident technique was used to help students to focus on their information behaviour during the task of information gathering for theses. If an item was available in an electronic version either from the NTU Library or from the internet, students were asked whether they used the electronic version. A list of databases relating to the student's research discipline was also shown to assist in recalling the situation. Each interview was recorded and lasted one hour on average.

National Taiwan University is a research-oriented university founded in 1928. The library holds the largest research collections in Taiwan. According to 2007 statistics (National Taiwan University Library, 2008), the Library owns 3,278,496 volumes of books (1,388,333 in Chinese and Oriental languages; 1,890,163 in western languages), 10,720 current print journal titles, 667,999 e-book titles, 27,023 current e-journal titles, and 391 databases. In 2006 the library began the process of making e-journals accessible on Google Scholar and uploading e-books' bibliographic records to its online catalogue. At the time of this study those tasks were still works in progress with incomplete collections of links.

\section{Results of the citation analysis \\ Type of cited documents}

Table I shows that a total of 2,550 items were cited in 20 theses. The students cited more books (69.1 per cent) than journals (25.4 per cent), theses (3.4 per cent) or other types of materials. Web citations ( 0.5 per cent) were surprisingly low, appearing in only six theses. Proceedings were seldom cited. The types of documents cited by linguistics students somewhat differed from those of students in other disciplines. One linguistics student cited more journals (70.3 per cent) than books (17.8 per cent).

Table II shows that documents in Chinese ( 54.5 per cent) were cited more than documents in English (38.9 per cent). There were variations among disciplines. For example, students of linguistics and foreign languages and literature cited more English documents than Chinese documents. Students of Japanese language and literature cited more Japanese documents than students in other disciplines. One student of art history also cited a large number of Japanese documents. 
OIR

34,3

\section{2}

Table II.

Document language and age

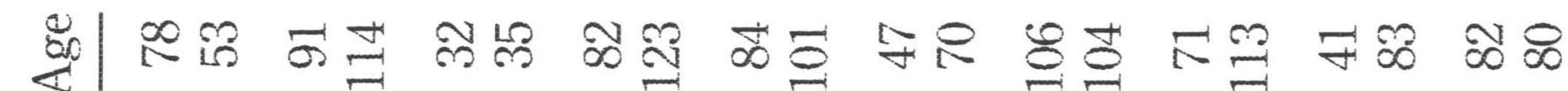

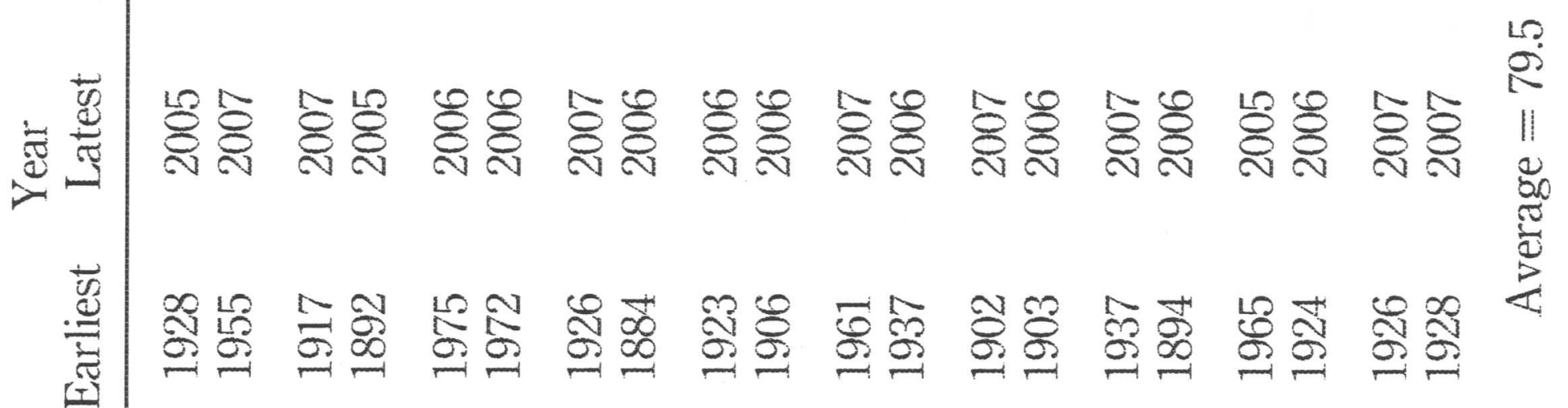

过 我

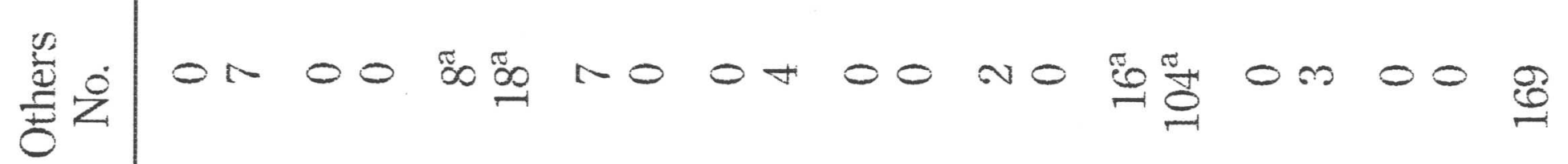

ब

总

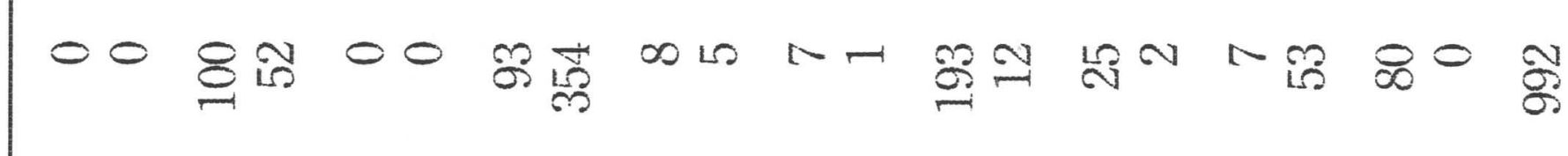

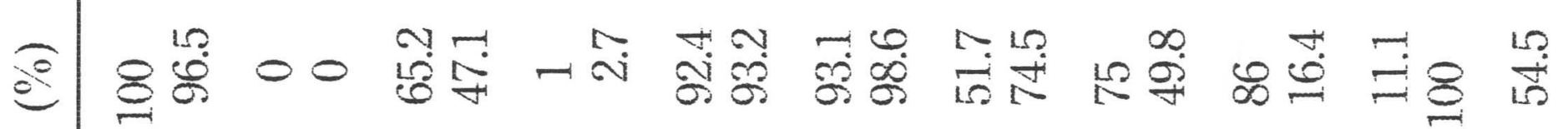

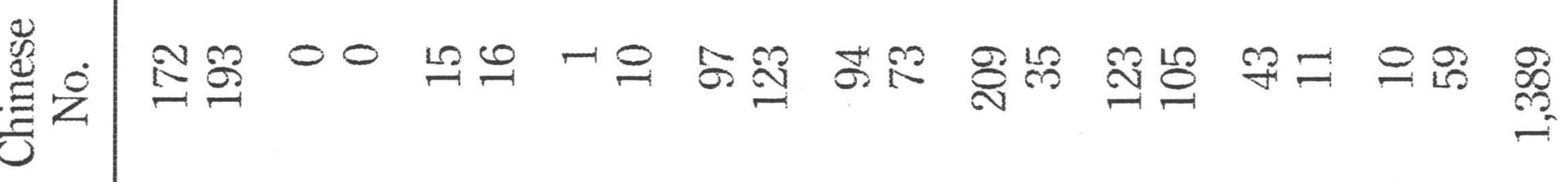

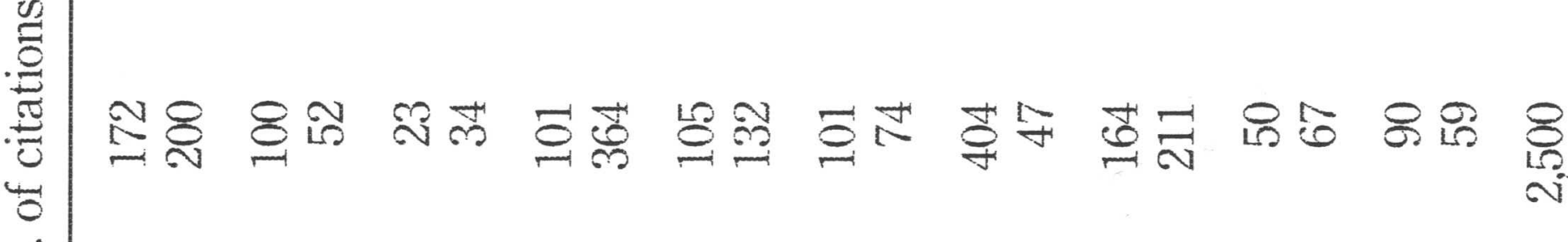

$-N$ m

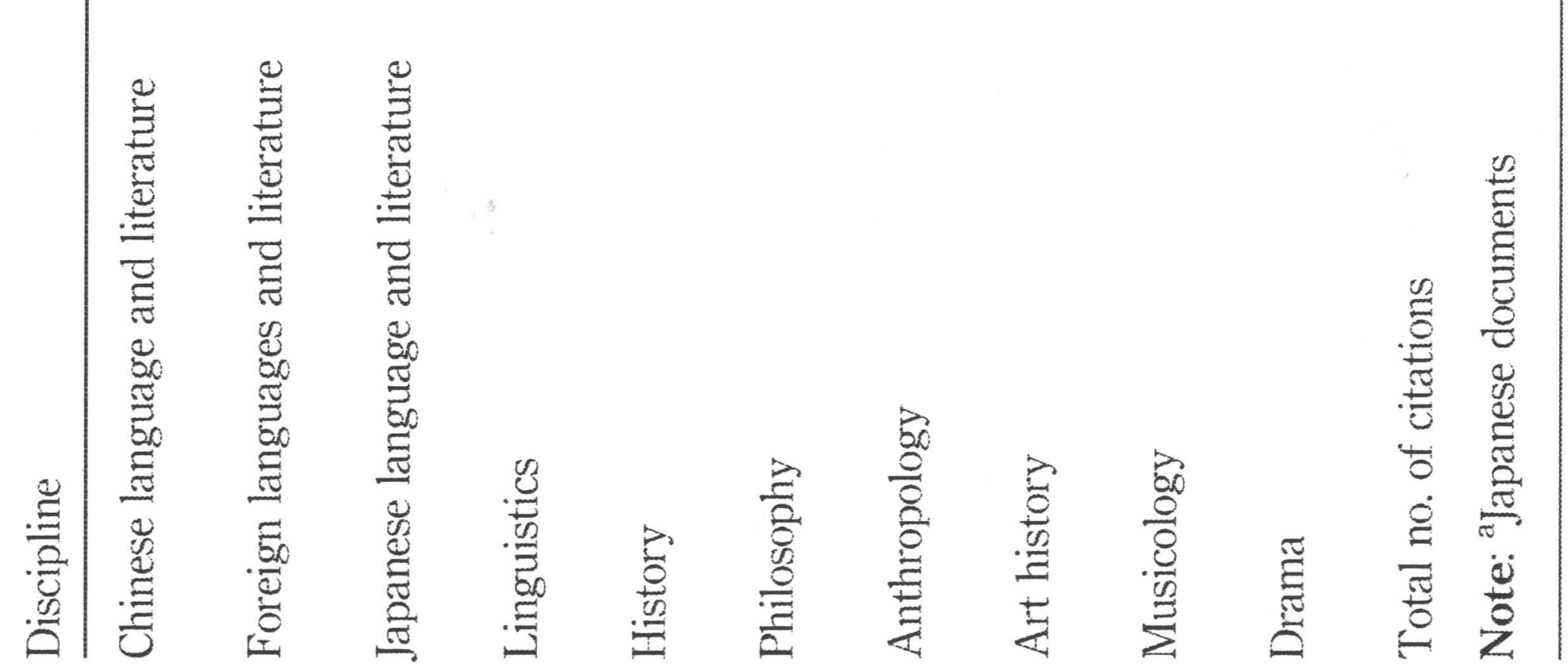


The students used old as well as current documents in their theses. The dates of cited documents spanned the nineteenth to twenty-first centuries. The earliest document cited was dated 1892, and the average document age was 79.5 years. Without exception, students from all humanities cited at least one document, which dated back 33 years. Six students cited documents spanning more than 100 years. However both theses in Japanese language and literature cited documents that were more current than those of other disciplines (see Table II).

\section{Availability of cited documents}

Table III shows that NTU Library supplied 74 per cent of the documents (print and electronic) that the students cited. The library held 80.6 per cent of the journal articles cited, 74.8 per cent of the books, and 40.7 per cent of the theses. Again there were differences among disciplines. For example the book availability ratios of one thesis in Japanese language and literature and one of musicology were below 50 per cent.

Table III also shows that 244 (9.6 per cent) of the 2,550 cited items were available in an electronic format from NTU Library. Students cited more books than journals, but their availability ratios were 1.2 per cent and 33 per cent respectively. It is clear that students could obtain many more electronic journals than books from the Library.

If an item was unavailable in the Library, there were several possible ways students could obtain it, such as a request via interlibrary loan, borrowing from advisors, buying it themselves etc. However, the internet was the most likely alternative because of the free availability of scholarly documents. Using Google tools to search the internet, it was found that only a minority of the documents (15 per cent) were available. The availability ratio of journals (36.1 per cent) was much higher than that of books (7 per cent) (see Table IV). The journal availability ratio was higher because some full-text documents that were not electronically available from the library were accessible via Google.

\section{Interview results}

Sources used to gather information

Before gathering documents, students needed to find out the locations of those documents related to their research topics. Unsurprisingly all 20 students used the NTU Library's $\mathrm{OPAC}$, databases, and Google tools to retrieve bibliographic sources. The library OPAC and databases are primary sources. Six students said they used Google tools occasionally. It is worth mentioning that 12 students indicated that their advisors provided core bibliographies which they used as a starting point, followed by a snowball approach to locate more information. Another eight students said they received help from advisors sometimes. In addition five students acquired bibliographic sources from their peers.

Although several studies have revealed that the internet is the first choice for most people who seek information, this study found that humanities graduate students instead regarded the library as their top source when gathering information for their theses. This result, can be explained, by the type of materials, that the students used. The citation analysis in this study indicated that 69.1 per cent of their references were books. Furthermore compared with journal articles and other materials, there were fewer full-text books accessible on the internet. All but one student clearly indicated that they predominantly depended on the collections of NTU Library. A student of musicology collected most of the sources she needed from libraries in Malaysia because the NTU Library did not hold enough materials related to her thesis topic. In order to 
OIR

34,3

464

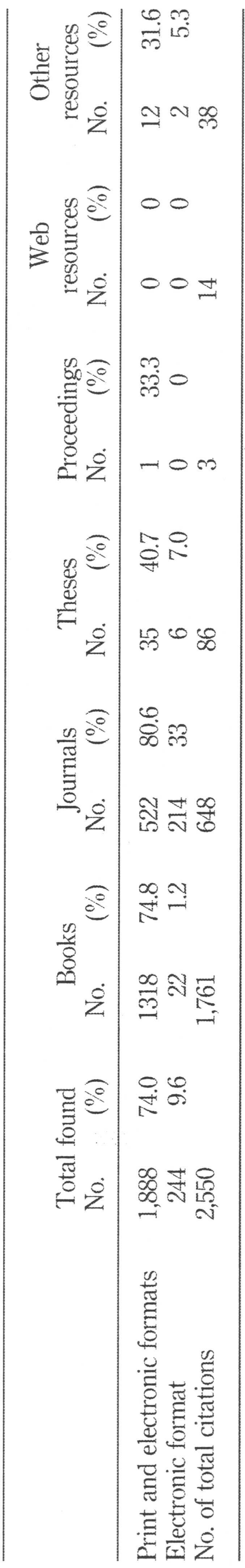

Table III.

Documents found in NTU

Library 
access more comprehensive collections, four students even visited libraries in other countries, such as Mainland China, Japan, or the United States, in addition to local libraries.

All students stated that they used Google, however they each mentioned different purposes. One student of art history used Google to update biographical information about a contemporary artist. One drama student said she used Google to update information about productions by a dramatist. Five students said that they used Google to verify bibliographic information. Google Scholar was popular among some humanities graduate students. They used it to retrieve e-journal articles and get more information about citing articles. However six students commented that they rarely used Google Scholar because it collected relatively few Chinese materials. A few students used Google Book Search to browse the contents or read part of a book in order to decide whether to check out the printed version from the library. One student of foreign languages and literature particularly valued Google Book Search because she could use it to find many western classics unavailable at the NTU Library. "One-third of the books which I cited came from Google Book Search", she reported. Google Maps was another tool mentioned by an anthropology student. Generally speaking humanities graduate students appreciated the convenience of Google tools; however most of them did not regard Google as a primary information source.

When materials were not available at the library

Humanities graduate students would try all possible sources to obtain materials they needed. They generally moved from source to source if they determined the material was largely relevant. When materials were unavailable at NTU library, 15 students said they used the interlibrary loan service provided by the library. Another five students never used the service because it was too expensive and slow, and the loan period was too short. All students mentioned that they visited and borrowed books in person from other local libraries.

In Taiwan patrons, rather than libraries, pay the interlibrary loan (ILL) service fees, which cost US\$0.16 per article page and US\$3 per book. Humanities graduate students usually need many sources when working on their theses. Ten students mentioned that they preferred to visit and borrow from other libraries in person to avoid the costly ILL fees. Apart from the cost incentive, several students explained that they visited other libraries because they liked to browse the shelves in order to find more relevant materials.

The ILL delivery time usually ranges between three and ten days. Students reported that if the materials were available at a nearby library, it would be quicker to go there in person to borrow them. Because humanities graduate students spent more time reading books, they complained that the three or four week loan period was too short. Most (14) students purchased books if they found those books to be of importance.

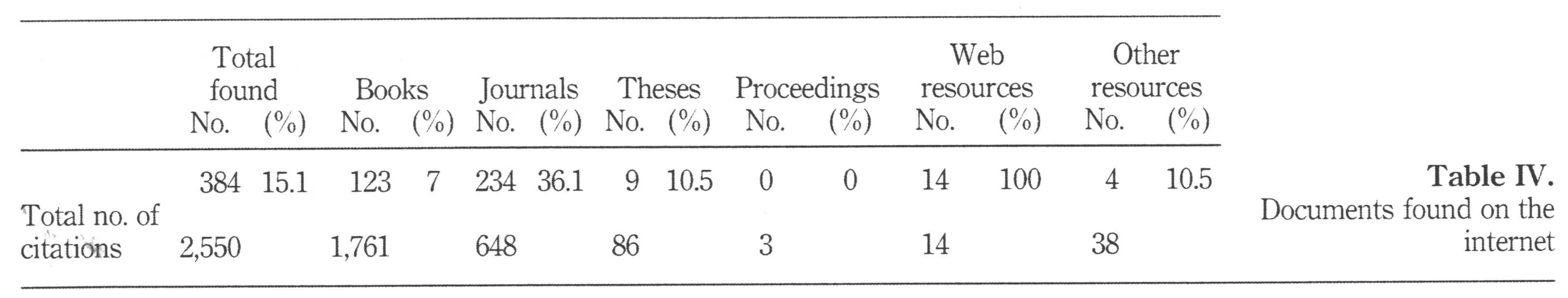


OIR

34,3
A Chinese language and literature student reported that she spent "a lot of money" building a personal collection of books.

Most (14) students mentioned that their advisor's personal collection was an important alternative source when materials were not available from the libraries. It is not unusual for humanities scholars to have large personal collections. "My advisor's office is just like a small library", reported a philosophy student. Several students mentioned that they borrowed old or rare books from their advisors. Occasionally students borrowed materials from their peers as well.

\section{Use of the library's electronic resources}

NTU Library holds the largest academic collection in Taiwan. Students appreciate that the library provides a significant quantity of electronic resources. Only two students, both majoring in Japanese language and literature, criticised the insufficiency of Japanese electronic resources in the library. All students agreed that it was convenient to use electronic resources because they could retrieve a large amount of information within a short time period. However they did mention some usage problems, Databases, e-journals, e-books, and e-theses and dissertations were listed on the Library's web site along with other electronic resources. Two students noted that they sometimes could not decide where to start when they wanted to find a journal article or a monograph because they thought the databases might also contain some e-journals and e-books.

To access to certain Chinese databases, one must download and install software. Several students reported that the downloading process was complicated and sometimes unsuccessful. A few students indicated that it was difficult to key in old or special Chinese characters on the computer when searching Chinese databases. Moreover when they searched non-Chinese databases, they sometimes had problems choosing the appropriate romanised Chinese or Oriental personal or place names. The same problem occurred when searching for specific Chinese and Oriental terms.

Humanities graduate students used e-journals more often than other types of electronic resources. One student complained that the earlier issues of some journals were not available in electronic format. The journals held by the library have not all had their back issues completely uploaded, either because the library did not subscribe to them then or the publisher has not digitised all the back issues. Students also mentioned the embargo of current journal issues as another problem. Students also mentioned that there were fewer Chinese journals accessible online.

As mentioned previously, humanities graduate students cited more books than other types of documents in their theses. In addition to Chinese e-books the NTU Library subscribed to NetLibrary and other western e-book databases. While students used e-books, they preferred e-journals. They indicated that they would usually need to spend more time reading a book and that it was inconvenient to read it online.

Students did, however, read short documents online, even though most preferred to read paper copies. Nearly all (17) students said they would browse and filter the documents online before printing them out. Some sources were only available in electronic format in the library's holdings. The students said that they would like the library to provide paper versions of e-books. Eight students felt that reading journal articles online was acceptable because they are shorter than e-books.

When using ancient Chinese books, six students said they would check the electronic version against the paper version to ensure the accuracy of the electronic version. 
A student of art history reported that her advisor insisted on her checking both versions. Three students said they would check the paper version if the electronic version had been keyed in manually instead of scanned and digitised. They always questioned the accuracy of electronic versions of Chinese ancient books because of the typographical errors, which occur in almost all Chinese databases. Many Chinese ancient books include old or rarely used Chinese characters. Different database creators may use different processing methods, which result in unreadable characters onscreen. Students also voiced concern over the authority of the versions of digitised old books. Yet the majority of the students interviewed did not believe there were discrepancies between the versions or simply did not regard comparing the versions as a necessity.

Almost all university libraries are in the process of expanding their electronic collections. Students' opinions on books and journals were diverse. They were willing to accept that e-journals could replace paper versions. However with regard to books, 13 students insisted that paper versions were irreplaceable, although they conceded that e-books could coexist with paper versions. The convenience of reading and browsing books was their primary concern. Since only authenticated patrons are permitted to access the library's electronic resources, students also worried that they would be unable to access documents after graduation if only electronic versions were available.

\section{Citing electronic resources}

NTU Library owned both paper and electronic versions of some documents cited by the students. Some of the students interviewed used electronic versions when writing their theses. However such usage was not always accurately represented in the "References" section. Five students reported that if both versions were available, they would cite the paper version even if they actually used the electronic version because of departmental preferences. Four students explained that they cited paper versions in their bibliographies because they always checked the paper version after using an electronic version. Two students stated that they accurately cited whatever version they used.

\section{Discussion}

In confirmation of previous studies, this study found that humanities graduate students cited more books than journals. The NTU Library supplied 74 per cent of the documents students cited. The availability ratios in the disciplines of Japanese language and literature, musicology, and drama were lower than that of other disciplines. This is understandable because the institutes of these three disciplines only deliver masters programmes and were founded after 1994, later than other institutes. Although the library owns the largest research collections in Taiwan, its collections in these particular disciplines are insufficient, and its current and retrospective collections must be developed.

Several studies have indicated that students prefer to use Google, rather than libraries, to find information. However the results of this study clearly indicate that the library is still the primary and major source for humanities graduate students when gathering information for their theses. They used the local library's OPAC and databases to retrieve bibliographic sources. They obtained over 70 per cent of the documents cited from the local library. They also acquired documents from other local libraries or libraries abroad.

When humanities graduate students were gathering information, their advisors played a very important role. More than half of the students interviewed indicated that
Impact of ER on student theses 
their advisers supplied bibliographic references related to their research topics, and they also lent documents to students from their own personal collections. Mentorship is a respected tradition in the humanities in Taiwan and the rest of Asia. Advisors usually have a strong sense of responsibility to help. They often choose their students' research topics and provide core bibliographies as starting points. Humanities scholars usually own large personal research collections that typically number over 3,000 titles, i.e. a small library. The advisor may own rare books, manuscripts, or old documents, which have not otherwise been collected in the libraries. This is one reason why many students borrowed documents from their advisors. Although a few students indicated that they occasionally borrowed documents from their peers or asked friends abroad to make photocopies, most humanities graduate students seeking guidance looked to their advisors, who played a key role in their social networks. This study's results confirms those of George et al. (2006), which indicated that professors and advisors recommend and supply resources to graduate students and play a central role in their information seeking processes. In addition humanities graduate students followed their advisors' example; a few students interviewed said they purchased books and built their own personal collection.

Browsing is a very significant behaviour among humanities graduate students gathering information. Half (ten) of the students mentioned that they preferred to visit local libraries instead of using the interlibrary-loan service. They explained that the main advantage of physical libraries was being able to browse the shelves. Several students claimed they also preferred to purchase books from physical rather than online book vendors.

Although more and more scholarly electronic resources are available from the library, and internet, they are not as fundamental as might be expected. Humanities graduate students cited a relatively small number of electronic resources. The majority of their citations were printed documents. However they used the electronic resources owned by the NTU Library as well as Google tools to retrieve documents. To compare with other academic disciplines, there are fewer electronic resources available in the field of humanities. Many studies, including this one, show that humanities scholars and students use more books than journals. Documents used by humanities scholars or students may date back 30,50, or over 100 years. Although there are international digitised projects in the humanities and several publishers are distributing classics databases, the overall amount of available digitisations still fails to meet academic needs. Accomplishing the digitisation of millions of scholarly books spanning several thousand years is not an easy job and will take a long time. Of course e-book databases have undeniably helped students to acquire early classics, which may have been otherwise unavailable from a local library.

The significance of electronic resources in general cannot be accurately determined from the citation analysis of humanities graduate students' theses. However the interview content may enhance the quantitative results. First, quite a few students checked citations against paper versions after using electronic versions, but they chose to cite the bibliographic information of the former. Second, departmental style regulations required paper citations, even if the student used the electronic version. Third, the conventions for citing electronic resources are not commonly understood or accepted in the humanities. Finally, the accuracy of electronic resources is questioned by a number of humanities scholars, especially senior scholars. A student of Chinese 
language and literature confided that although she had only read the electronic version, she cited the paper version because her advisor only accepted citations of print sources.

Google tools are important to humanities graduate students. However, students usually regarded them as ready-reference tools. They used Google tools to look for definitions or to update biographical information. More frequently they used Google tools to locate or verify bibliographic information. Students seldom retrieved full-text documents from the internet, perhaps because there are fewer Chinese scholarly resources in the humanities freely available on the internet. For example fewer Chinese student theses books than English books could be found via Google Book Search. Meanwhile only a small proportion of NTU Library's e-journal titles were accessible from Google Scholar. Although they used Google tools and other electronic resources infrequently and sometimes encountered usage problems, all students praised their convenience.

Lee (2003) divided university professors' information spaces into varying degrees of accessibility (immediate, adjacent and outside). Investigating the preferences of internet users, Savolainen and Kari (2004) categorised users' information sources into three zones based on the accessibility and quality of sources preferred. Electronic resources are highly accessible, however the role of electronic resources, including Google tools, is not so obvious. Accessibility was not a key factor in the information gathering and use behaviour of humanities graduate students. They did not depend heavily on or frequently use electronic resources. When searching for sources, they used the library OPAC and databases most frequently and obtained their most useful documents from the library's print collection. Based on the previous findings and discussion, the information horizons for humanities graduate students are portrayed according to frequency of use in Figure 1.

\section{Conclusions}

Theses are the final academic products of graduate students. By examining the cited references, this study could determine the characteristics of the documents used. This study also analysed the students' behaviour on completion of information gathering.

Electronic resources have undoubtedly affected humanities graduate students. Nevertheless physical books remain their primary sources of research. When expanding e-book collections, libraries should supplement rather than replace their paper collections. University libraries should take the acceptance of e-journals into consideration when building their humanities electronic collection. Attention should also be paid to the humanities faculty's attitudes to electronic resources because they may affect students' behaviour. Variations of information gathering and use patterns among disciplines must also be recognised.

Google is not the first step for humanities graduate students when gathering research information. Google Scholar is not a frequently used research tool for humanities graduate students. Nevertheless many libraries will continue to upload their collections to Google Scholar because Google tools may become increasingly popular in the near future. Further studies should be made on their effects on humanities scholarship.

Studies on usage and users will certainly be important while university libraries continue to increase their expenditure on electronic collections. While citation analysis alone has its limitations, it can offer a comprehensive picture of information gathering and use behaviour of humanities graduate students if used in combination with list-checking and follow-up interviews. 
OIR

34,3

470

Figure 1.

Information horizons for humanities graduate students
Bibliographic sources Documents

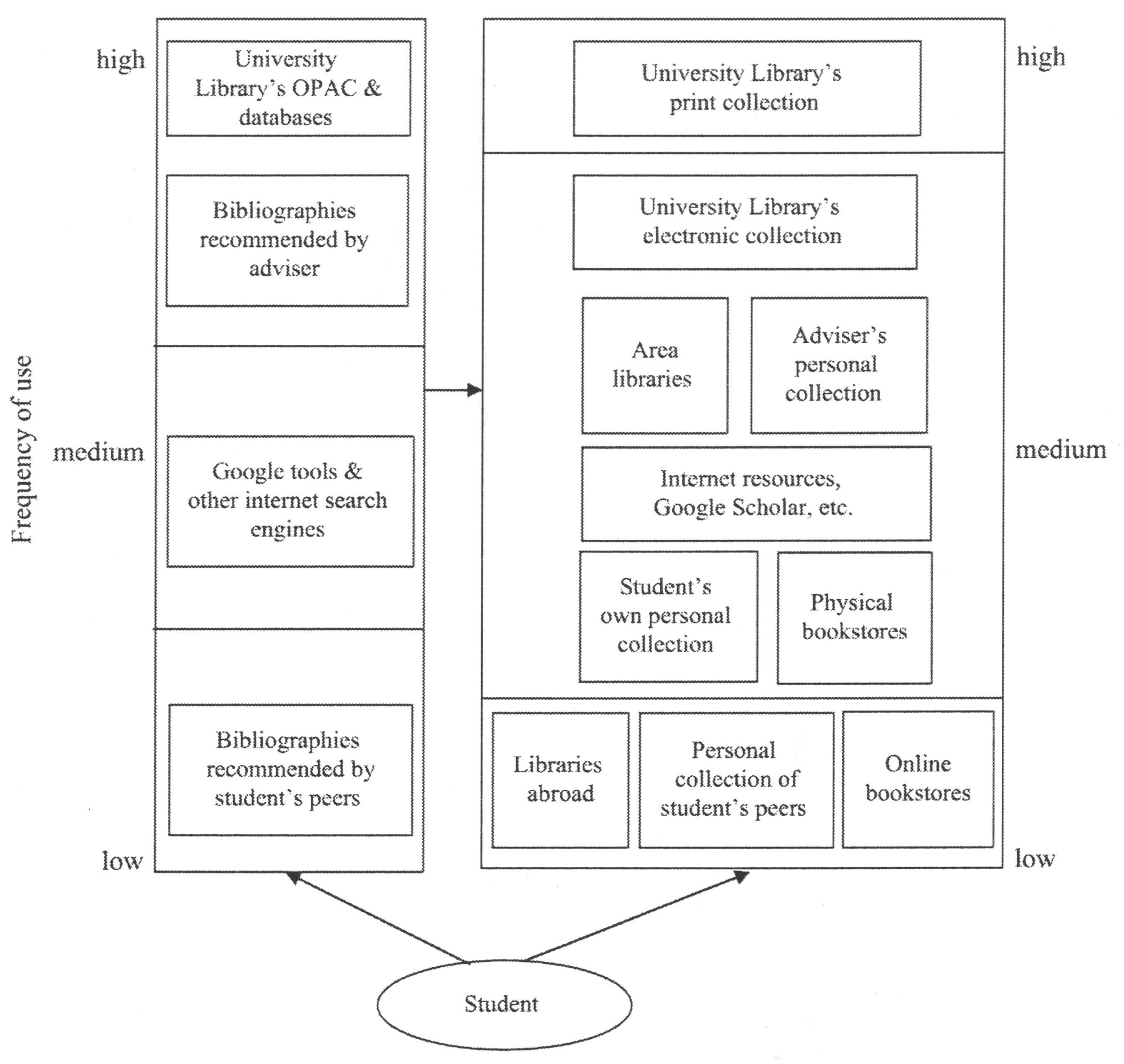

References

Anderson, F.E. (2009), “Using professional forums to assess historians' e-resource needs", Collection Building, Vol. 28 No. 5, pp. 4-8.

Buzzard, M.L. and New, D.E. (1983), "An investigation of collection support for doctoral research”, College \& Research Libraries, Vol. 44 No. 6, pp. 469-75.

Case, M.M. (2005), “A snapshot in time: ARL libraries and electronic journal resources”, Journal of Library Administration, Vol. 42 No. 2, pp. 87-105.

Cox, J.E. (2008), "Citation analysis of graduate dental theses references: implications for collection development", Collection Management, Vol. 33 No. 3, pp. 219-34.

Gallagher, J., Bauer, K. and Dollar, D.M. (2005), "Evidence-based librarianship: utilizing data from all available sources to make judicious print cancellation decisions", Library Collections, Acquisitions, and Technical Services, Vol. 29 No. 2, pp. 169-79.

Gardiner, D., McMenemy, D. and Chowdhury, G. (2006), "A snapshot of information use patterns of academics in British universities", Online Information Review, Vol. 30 No. 4, pp. 341-59.

George, C., Bright, A., Hurlbert, T., Linke, E.C., St Clair, G. and Stein, J. (2006), "Scholarly use of information: graduate students' information-seeking behaviour", Information Research, 
Vol. 11 No. 4, available at: http://works.bepress.com/carole_george/1 (accessed 15 July 2009).

Harter, S.P. (1998), "Scholarly communication and electronic journals: an impact study", Journal of the American Society for Information Science, Vol. 49 No. 6, pp. 507-16.

Hemminger, B., Lu, D., Vaughan, K. and Adams, S. (2007), "Information-seeking behavior of academic scientists", Journal of the American Society for Information Science \& Technology, Vol. 58 No. 14, pp. 2205-25.

Herring, S.D. (2002), "Use of electronic resources in scholarly electronic journals: a citation analysis", College \& Research Libraries, Vol. 63 No. 44, pp. 334-40.

Huang, H-C. (2008), "University and college libraries", Library Yearbook of the Republic of China, National Central Library, Taipei, pp. 85-110 (in Chinese).

Jamali, H.R., Nicholas, D. and Rowlands, I. (2009), "Scholarly e-books - the views of 16,000 academics: results from the JISC National E-books Observatory”, Aslib Proceedings: New Information Perspectives, Vol. 61 No. 1, pp. 33-47.

Kushkowski, J.D. (2005), "Web citation by graduate students: a comparison of print and electronic theses", Portal: Libraries and the Academy, Vol. 5 No. 2, pp. 259-76.

Lee, H-L. (2003), "Information spaces and collections: implications for organization", Library \& Information Science Research, Vol. 25 No. 4, pp. 419-36.

Levine-Clark, M. (2007), "Electronic books and the humanities: a survey at the University of Denver", Collection Building, Vol. 26 No. 1, pp. 7-14.

Liew, C.L., Foo, S. and Chennupati, K.R. (2000), "A study of graduate student end-users' use and perception of electronic journals", Online Information Review, Vol. 24 No. 4, pp. 302-15.

Littman, J. and Connaway, L.S. (2004), "A circulation analysis of print books and e-books in an academic research library”, Library Resources \& Technical Services, Vol. 48 No. 4, pp. 256-62.

Liu, Z. (2006), "Print vs electronic resources: a study of user perceptions, preference, and use", Information Processing and Management, Vol. 42 No. 2, pp. 583-92.

National Taiwan University Library (2008), 2006-2007 Annual Report, National Taiwan University Library, Taiwan, available at: www.lib.ntu.edu.tw/General/publication/ LibraryAnnualReport_2006-2007.pdf (accessed 10 July 2009).

Newby, J. (2005), "An emerging picture of mathematicians' use of electronic resources: the effect of withdrawal of older print volumes", Science \& Technology Libraries, Vol. 25 No. 4, pp. 65-85.

Okrent, n. (2001), "Use of full-text electronic resources by philosophy students at UNC-Chapel Hill: a citation analysis", Master's thesis, University of North Carolina, Chapel Hill, NC.

Prabha, C. (2007), "Shifting from print to electronic journals in ARL university libraries", Serials Review, Vol. 33 No. 1, pp. 4-13.

Reynolds, J. (1995), “A brave new world: user studies in the humanities enter the electronic age”, Reference Librarian, Vol. 23 Nos 49/50, pp. 61-81.

Rowlands, I. (2007), "Electronic journals and user behaviour: a review of recent research", Library \& Information Science Research, Vol. 29 No. 3, pp. 369-96.

Savolainen, R. and Kari, J. (2004), "Placing the internet in information source horizons: a study of information seeking by internet users in the context of self-development", Library \& Information Science Research, Vol. 26 No. 4, pp. 415-33. 
OIR

34,3
Siebenberg, T.R., Galbraith, B. and Brady, E.E. (2004), "Print versus electronic journal use in three sci/tech disciplines: what's going on here?”, College \& Research Libraries, Vol. 65 No. 5 , pp. $427-38$.

Smith, E.T. (2003), "Assessing collection usefulness: an investigation of library ownership of the resources graduate students use", College \& Research Libraries, Vol. 64 No. 5, pp. 344-55.

Stone, S. (1982), "Humanities scholars: information needs and uses", Journal of Documentation, Vol. 38 No. 4, pp. 292-313.

Sutton, A.M. and Jacoby, J. (2008), “A comparative study of book and journal use in four social science disciplines”, Behavioral \& Social Sciences Librarian, Vol. 27 No. 1, pp. 1-33.

Talja, S. and Maula, H. (2003), "Reasons for the use and non-use of electronic journals and databases: a domain analytic study in four scholarly disciplines", Journal of Documentation, Vol. 59 No. 6, pp. 673-91.

Tenopir, C. (2003), Use and Users of Electronic Library Resources: An Overview and Analysis of Recent Research Studies, Council on Library and Information Resources, Washington, DC.

Thompson, J.W. (2002), "The death of the scholarly monograph in the humanities? Citation patterns in literary scholarship", Libri, Vol. 52 No. 3, pp. 121-36.

Vakkari, P. and Talja, S. (2006), "Searching for electronic journal articles to support academic tasks: a case study of the use of the Finnish National Electronic Library (FinELib)", Information Research, Vol. 12 No. 11, available at: http://informationr.net/ir/12-1/paper285. html (accessed 20 July 2009).

Walcott, R. (1994), "Local citation studies: a shortcut to local knowledge", Science \& Technology Libraries, Vol. 14 No. 3, pp. 1-14.

Wang, Y.K. (2006), "Information behaviours in the digital environment: a case study of humanities and social science scholars", Master's thesis, University of Alberta, Edmonton, $\mathrm{AB}$.

Wu, M-D. and Chen, S-C. (2007), "Humanities graduate students' use behavior on full-text databases for ancient Chinese books", Lectures Notes in Computer Science, No. 4822, pp. 141-9.

Zhang, Y. (2001), "Scholarly use of internet-based electronic resources", Journal of the American Society for Information Science and Technology, Vol. 52 No. 8, pp. 628-54.

\section{About the authors}

Ming-der Wu is currently a Professor in the Department of Library and Information Science, National Taiwan University. His research interests include collection development, information organisation, management of electronic resources, and information-seeking behaviour in the academic context. Ming-der $\mathrm{Wu}$ is corresponding author and can be contacted at: mdwu@ntu.edu.tw

Shih-chuan Chen is currently a doctoral student in the Department of Library and Information Science, National Taiwan University.

To purchase reprints of this article please e-mail: reprints@emeraldinsight.com Or visit our web site for further details: www.emeraldinsight.com/reprints 